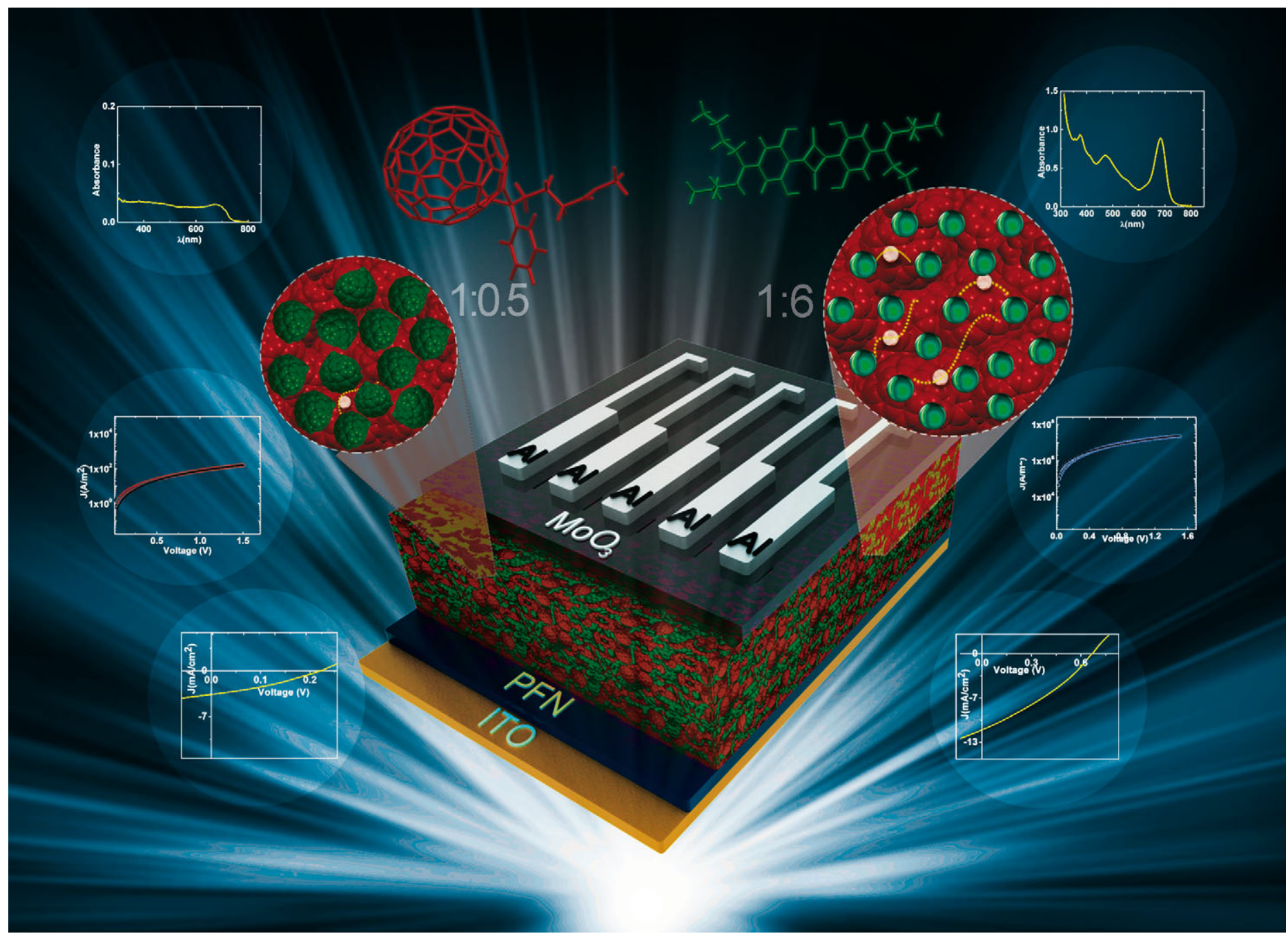

Showcasing research from the Molecular Opto and Bio Electronics Laboratory of School of Physics at Indian Institute of Science Education and Research Thiruvananthapuram (IISER-TVM), India.

Title: Squaraine based solution processed inverted bulk heterojunction solar cells processed in air

Headed by Dr Manoj A. G. Namboothiry, the group explore the possibility of making devices such as solar cells, light emitting diodes, photo transistors, and memory devices. Incorporation of plasmonic nanostructures, photocurrent spectroscopy, conducting polymer/bio molecular interface for bio sensor applications are major areas of focus of our group. Conjugated polymers, small molecules, and perovskites are some of the materials of interest. In this paper, the effect of the dispersion of squaraine $(S Q)$ in a PCBM matrix on the photovoltaic properties of SQ:PCBM bulk heterojunction solar cells is investigated.

\section{As featured in:}

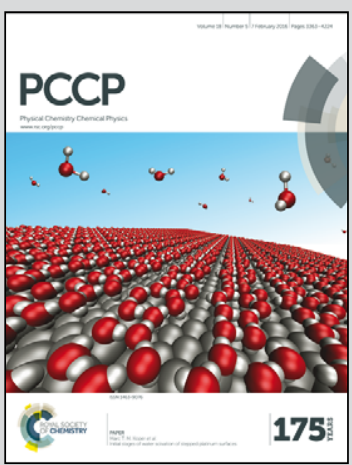

See P. C. Reshmi Varma and Manoj A. G. Namboothiry, Phys. Chem. Chem. Phys., 2016, 18, 3438.

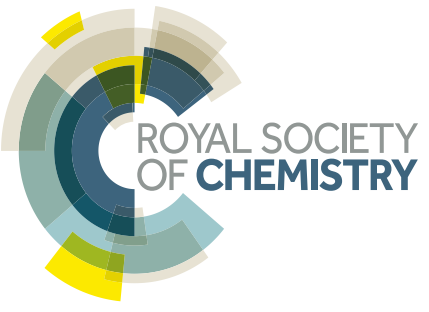




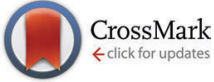

Cite this: Phys. Chem. Chem. Phys., 2016, 18, 3438

Received 26th August 2015, Accepted 21st September 2015

DOI: $10.1039 / \mathrm{c5cp05080d}$

www.rsc.org/pccp

\title{
Squaraine based solution processed inverted bulk heterojunction solar cells processed in air $\hat{\dagger}$
}

\author{
P. C. Reshmi Varma and Manoj A. G. Namboothiry*
}

\begin{abstract}
Inverted bulk heterojunction solar cells based on low temperature solution processed squaraine (SQ) and $[6,6]$-phenyl $C_{71}$ butyric acid methyl-ester $\left(P C_{71} B M\right)$ with varying blend ratios were made in air. An optimized bulk heterojunction device of $S Q$ and $\mathrm{PC}_{71} \mathrm{BM}$ (with a blend ratio of 1:6) showed a power conversion efficiency (PCE) of $2.45 \%$ with an incident photon to current conversion efficiency of $65 \%$ at $680 \mathrm{~nm}$ and a spectral window extending to the NIR region. The devices also showed an enhanced PCE value of 4.12\% upon continuous illumination from an AM1.5G light source of intensity 1 Sun. The intensity dependent photocurrent studies showed a monomolecular recombination mechanism in the photovoltaic device performance. The device stored in air showed reasonable stability for a period of one month.
\end{abstract}

\section{Introduction}

Squaraines (SQNs) are a class of small molecular organic dyes which were reported in $1965^{1}$ and are widely used in different applications such as sensing, ${ }^{2}$ imaging, ${ }^{3}$ nonlinear optics, ${ }^{4,5}$ and photovoltaics ${ }^{6,7}$. Small molecule based high performance photovoltaic research has gained significant momentum during the last few years due to its advantages, such as being intrinsically monodispersive, easy to synthesize with a good batch to batch reproduction, ease of purification ${ }^{8,9}$ and easily controlled band gap compared to polymers. It is also to be noted that the effect of parameters such as regioregularity, polydispersity and stability on polymer based photovoltaic devices have not been fully understood. SQN with all the properties of a small molecule is a promising candidate to be used as an active donor material in small molecule based organic photovoltaics (OPVs). SQN also shows a broad spectral response extending to the near infrared (NIR) wavelength $(\lambda)$ region $(450 \mathrm{~nm}<\lambda<800 \mathrm{~nm}),{ }^{10}$ large absorption coefficient $\left(\alpha \sim 3 \times 10^{5} \mathrm{~cm}^{-1}\right)^{11}$ and stability, which are advantageous to OPV performances. Initially SQN based OPV devices used a bilayer structure with thermally evaporated SQN as a donor and phenyl- $\mathrm{C}_{61}$-butyric acid methyl ester $\left(\mathrm{PC}_{61} \mathrm{BM}\right)$ as an acceptor layer. ${ }^{12}$ Since the exciton diffusion length was very low $\left(L_{\mathrm{D}}<5 \mathrm{~nm}\right)$, an interpenetrating bulk heterojunction (BHJ) approach was used for co-thermal deposition of SQN and

School of Physics, Indian Institute of Science Education and Research

Thiruvananthapuram, CET Campus, Engineering College P O,

Thiruvananthapuram, Kerala, PIN 695016, India.E-mail: manoj@iisertvm.ac.in

$\dagger$ Electronic supplementary information (ESI) available: Comparison of UV-VIS absorbance data of pristine SQ and SQ:PCBM blends of the same thickness, SCLC fitting of dark $I V$ characteristics of hole only devices, Dark $I-V$ characteristics of devices and the rectification ratio of the devices. See DOI: 10.1039/c5cp05080d [6,6]-phenyl $\mathrm{C}_{71}$ butyric acid methyl-ester $\left(\mathrm{PC}_{71} \mathrm{BM}\right)$ to improve the exciton dissociation. ${ }^{13}$ In order to improve the ease of OPV fabrication and keeping in mind the roll to roll processing of OPVs, solution processed SQNs were developed and BHJ devices were made using spin coating of different ratios of SQN : $\mathrm{C}_{60}$ or $\mathrm{C}_{70}$ blend solutions. ${ }^{14-16}$ Various interfacial layers were used to enhance the power conversion efficiencies of such $\mathrm{BHJ}$ devices. Molybdenum trioxide $\left(\mathrm{MoO}_{3}\right)$ and poly(3,4-ethylenedioxythiophene)-poly(styrene sulfonate) (PEDOT:PSS) are some of the hole transporting materials commonly used as buffer layers at the indium tin oxide (ITO)/polymer or the ITO/small molecule interface. But due to their highly hygroscopic nature, these materials can induce damage to ITO/PEDOT:PSS or ITO/ $\mathrm{MoO}_{3}$ interfaces and can introduce high series resistance to OPVs. As an alternative route, inverted solar cell structures were introduced to counter such deteriorating factors. To the best of our knowledge there have not been any reports to date of any application of inverted geometry in solution processed $\mathrm{BHJS}$ of SQN based devices.

Even though SQN is an air stable material, most of the devices reported in the literature were made in a controlled atmosphere. For the development of a cost effective fabrication technology, it is highly desirable to develop processes under normal atmospheric conditions without affecting device performance. In this article, we study an inverted solution processed BHJ OPV made from 2,4-bis[4-( $N, N$-diisobutylamino)-2,6-dihydroxyphenyl] squaraine (SQ) and $\mathrm{PC}_{71} \mathrm{BM}$ (Fig. 1a and b) using normal atmospheric processing. The inverted solar cells were fabricated using the configuration of ITO/PFN/SQ:PCBM/ $\mathrm{MoO}_{3} / \mathrm{Al}$. Poly[(9,9-bis(3'( $N, N$-dimethylamino)propyl)-2,7-fluorene)-alt-2,7-(9,9-dioctylfluorene)] (PFN) (Fig. 1c) was used as an interfacial layer between ITO and the SQ: $\mathrm{PC}_{71} \mathrm{BM}$ blend as it modifies the work function 


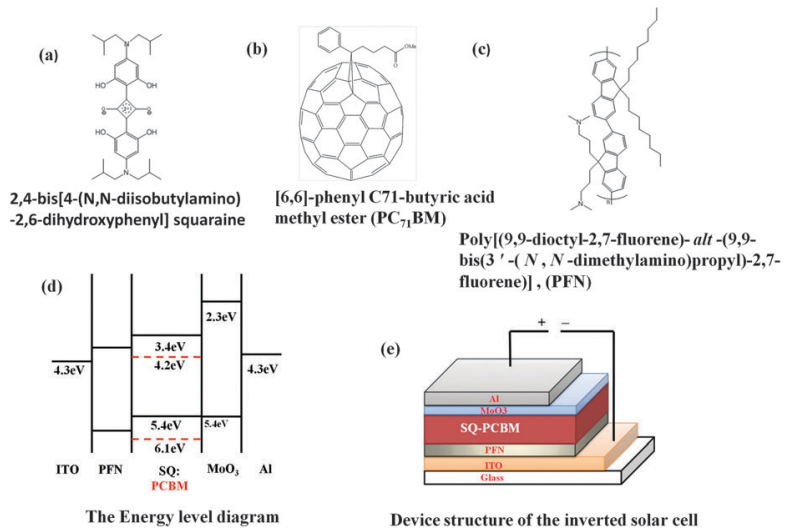

Fig. 1 Molecular structure of (a) squaraine, (b) $P C_{71} B M$, (c) PFN. Schematic of (d) the energy level diagram (e) the device structure of the inverted solar cell.

of ITO so that it can be used as a cathode in the inverted solar cell. $^{17,18}$ The low temperature solution processing property of PFN is advantageous compared to high temperature processed metal oxides as an interfacial layer for a wide range of applications and flexible substrates. The device structure and the energy level diagram are shown in Fig. 1d and e.

\section{Experimental section}

\section{Materials and methods}

All the chemicals and the substrates used for the fabrication were commercially purchased. The devices were fabricated on cleaned indium tin oxide (ITO) coated glass plates $\left(10 \Omega \mathrm{cm}^{-2}\right.$, Delta Technologies Inc, USA). Poly [(9,9-bis $\left(3^{\prime}-(N, N\right.$-dimethylamino)propyl)-2,7-fluorene)-alt-2,7-(9,9-dioctylfluorene)] (PFN, Purity $>99 \%$, 1 Materials Canada) was used to modify the work function of ITO to be used as a cathode in the inverted structure. Active layers were made using different blend ratios of 2,4 bis[4- $(\mathrm{N}, \mathrm{N}-$ diisobutylamino)-2,6-dihydroxyphenyl] squaraine (SQ, Purity $>99 \%$, Sigma Aldrich) and [6,6]-phenyl $\mathrm{C}_{71}$ butyric acid methyl-ester $\left(\mathrm{PC}_{71} \mathrm{BM}\right.$, Purity $>99 \%$, American Dye Sources, Canada) in orthodichlorobenzene (ODCB, Sigma Aldrich, HPLC grade). Thermally evaporated molybdenum trioxide $\left(\mathrm{MoO}_{3}\right.$, Purity $>99 \%$, Sigma Aldrich) was used as a hole transporting, electron blocking interfacial layer. Aluminum was used as a back contact, which was purchased from Sigma Aldrich.

\section{Device fabrication and characterization}

Devices were fabricated on an ITO coated glass substrate. ITO coated glass plates were cleaned with soap solution and ultrasonicated using deionized water, acetone and isopropyl alcohol for 30 minutes. Cleaned substrates were kept in a vacuum oven overnight for drying. Before spin coating the layers, ITO samples were exposed to UV ozone for about 30 minutes. On top of ITO substrates, PFN was spin coated, which was dissolved in methanol and mixed with acetic acid with a concentration of $0.2 \mathrm{mg} \mathrm{ml}^{-1}$ and then was spin coated at an rpm of 2000 to obtain a thin film of $\sim 5 \mathrm{~nm}$ and is used as an electron transporting, hole blocking layer. Active layers were made using different blend ratios of SQ: PCBM keeping a constant solution concentration ( $42 \mathrm{mg} \mathrm{ml}^{-1}$ ) to obtain a uniform thickness of active layers over different devices. The active layer solution was then spin coated (1500 rpm) over the thin PFN layer to form a layer of thickness $100 \mathrm{~nm}$. The thin layer of $(7 \mathrm{~nm}) \mathrm{MoO}_{3}$ evaporated at a pressure of $\sim 10^{-6}$ torr was used as a hole transporting, electron blocking interfacial layer. Aluminum (Al) of thickness $\sim 100 \mathrm{~nm}$ was thermally evaporated at a base pressure of $10^{-6}$ torr and was used as the top electrode. A device structure of ITO/PFN/SQ: $\mathrm{PC}_{71} \mathrm{BM} / \mathrm{MoO}_{3} / \mathrm{Al}$ was used for the solar cell studies. The thickness of spin cast films was measured using a Dektak stylus profilometer and that of thermally evaporated materials using an inficon thickness monitor. The active area of the device was $9 \mathrm{~mm}^{2}$. The devices were unencapsulated and all the measurements were performed under ambient conditions using samples mounted on a temperature controlled chuck. The sample temperature was maintained at $25^{\circ} \mathrm{C}$ and was monitored using a thermocouple.

The current-voltage characteristics of the devices were performed using a Keithley 6430 source meter in the dark and under the illumination of a $1000 \mathrm{~W} \mathrm{~m}^{-2}$ AM1.5G spectrum using an Oriel 3A solar simulator tested with a NREL calibrated silicon solar cell. The external quantum efficiency (EQE) measurements were carried out by a lock-in technique using a $250 \mathrm{~W}$ xenon lamp coupled with a Newport monochromator and chopped at $40 \mathrm{~Hz}$ using a light chopper blade as a light source. A lock-in amplifier (SRS 830, Stanford Research Systems Inc USA) was used to measure currents and a NIST calibrated silicon photodiode was used to find the power spectral response of the incident light. The measurements were performed using shadow masks to avoid edge effects and an appropriate mismatch factor was taken to square off the spectral mismatch for calculating the PCE and EQE. ${ }^{19,20}$ The intensity dependent measurements were performed using an AM1.5G, 1 Sun light source, in combination with neutral density filters of different optical densities.

\section{Results and discussion}

Different $\mathrm{SQ}: \mathrm{PC}_{71} \mathrm{BM}$ ratios were tested to obtain the best performance by considering high absorption coefficient, a broad spectral window extending up to $\lambda \sim 800 \mathrm{~nm}$ and a low exciton diffusion length $<6 \mathrm{~nm}$ of SQ and a large diffusion length and a poor absorption coefficient of $\mathrm{PC}_{71} \mathrm{BM}$.

The best results were obtained for an active layer of $\sim 100 \mathrm{~nm}$ thickness made from 1:6 blend ratios by weight of $\mathrm{SQ}: \mathrm{PC}_{71} \mathrm{BM}$ with an external quantum efficiency (EQE), varying from $45 \%$ to $65 \%$ in the spectral window extending to $\lambda \sim 800 \mathrm{~nm}$ and a power conversion efficiency (PCE) of $2.45 \%$. We fabricated more than 20 devices in each ratio and more than 50 best performing devices with a $\mathrm{SQ}: \mathrm{PC}_{71} \mathrm{BM}$ blend ratio of $1: 6$ by weight. The performance of organic photovoltaic cells depends on many parameters such as efficient light absorption, exciton creation, exciton dissociation, free carrier transport, and charge transfer to the electrodes. In order to understand the 

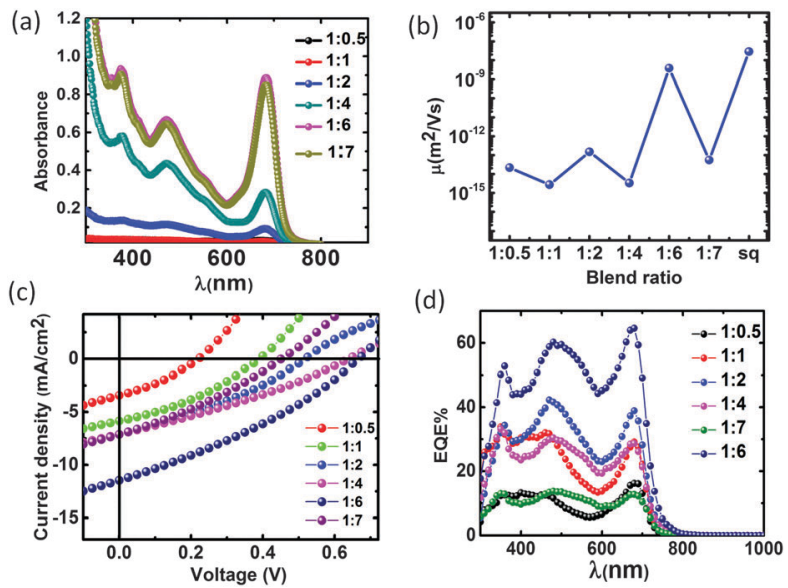

(d)

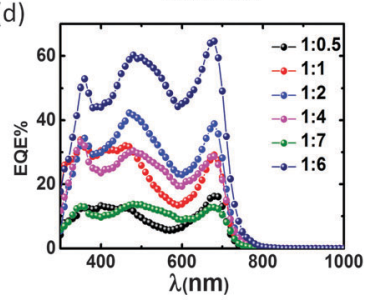

Fig. 2 (a) UV-Vis absorption of different ratios of $S Q: P C_{71} B M$ blend (b) hole mobility of squaraine in a pristine film and in a blend with $P_{71} B M$ in different ratios (c) current density vs. voltage $(J-V)$ characteristics of the $S Q: P C_{71} B M$ devices for different blend ratios, (d) $E Q E$ of $S Q: P C_{71} B M$ devices fabricated at different blend ratios.

above-mentioned factors, various electrical and optical measurements were carried out.

The UV VIS absorption spectra of $\mathrm{SQ}: \mathrm{PC}_{71} \mathrm{BM}$ for different blend ratios are shown in Fig. 2a. It is to be noted that we have measured the absorption spectra of thin films of the same thickness $(100 \mathrm{~nm})$ as we used in our devices for different blend ratio. The absorption strength of SQ at $\lambda \sim 683 \mathrm{~nm}$ steadily increases as the $\mathrm{SQ}: \mathrm{PC}_{71} \mathrm{BM}$ blend ratio is varied from $1: 0.5$ to $1: 6$. This is in spite of the fact that the weight content of SQ in the $1: 6$ blend ratio is much lower than that in the blend ratio of $1: 0.5$. This may be due to the well-known fact that SQ dimers or aggregates show lower absorption coefficients compared to monomers. ${ }^{21,22}$ Or in other words, in a $\mathrm{SQ}: \mathrm{PC}_{71} \mathrm{BM}$ blend ratio of $1: 6, \mathrm{SQ}$ is well dispersed in the $\mathrm{PC}_{71} \mathrm{BM}$ matrix with monomer like features and in other blends it is in dimeric or in aggregate form. A comparison of the UV VIS absorbance of pristine SQ thin films of $100 \mathrm{~nm}$ thickness with that of SQ: PCBM blends (1:0.5 blend ratio) is given in Fig. S1 (ESI $\dagger$ ). This result clearly shows the aggregation of SQ with a broadened absorption spectrum and the reduced absorbance of SQ only in thin films as compared to SQ: PCBM blends.

Along with other parameters, a balanced electron and hole mobility of $\mathrm{PC}_{71} \mathrm{BM}$ and SQ respectively is necessary to extract free carriers from the $\mathrm{BHJ}$ devices. In order to find the best blend ratio for achieving balanced hole and electron transport, $\mathrm{SQ}$ : $\mathrm{PC}_{71} \mathrm{BM}$ blends of different blend ratios were studied. SQ shows a hole mobility of $2.83 \times 10^{-4} \mathrm{~cm}^{2} \mathrm{~V}^{-1} \mathrm{~s}^{-1}$ in the pristine form and it further reduces in conjunction with $\mathrm{PC}_{71} \mathrm{BM}$. The hole mobility of SQ in the blend film is controlled by the hopping of holes through the SQ domains in the blend. ${ }^{23}$ Previous reports of zero field mobility of SQ suggest that the performance of the SQ: $\mathrm{PC}_{71} \mathrm{BM}$ blend was limited by its poor hole mobility through the discontinuous SQ networks compared to the electron mobility through the $\mathrm{PC}_{71} \mathrm{BM}$ networks. ${ }^{14}$ We also observe a similar result with the $\mathrm{SQ}: \mathrm{PC}_{71} \mathrm{BM}, 1: 6$ blend ratio, showing a hole mobility nearer to that of pristine SQ compared to other $\mathrm{SQ}: \mathrm{PC}_{71} \mathrm{BM}$ blend ratios. The improved hole mobility of $\mathrm{SQ}$ in $\mathrm{SQ}: \mathrm{PC}_{71} \mathrm{BM}$ of blend ratio 1:6 can be attributed to well dispersed SQ in the $\mathrm{PC}_{71} \mathrm{BM}$ matrix with SQ within the optimized hopping distance. ${ }^{23}$ This argument is speculated based on the SQ contribution to the UV VIS absorption of different $\mathrm{SQ}$ : $\mathrm{PC}_{71} \mathrm{BM}$ blend ratios and mobility studies. Fig. $2 \mathrm{~b}$ shows the variation of the hole mobility of SQ in different blend ratios of $\mathrm{PC}_{71} \mathrm{BM}$. We find that $\mathrm{SQ}: \mathrm{PC}_{71} \mathrm{BM}$ of the $1: 6$ blend ratio has a hole mobility much nearer to the electron mobility of $\mathrm{PC}_{71} \mathrm{BM}^{24,25}$ and expected to show better OPV performances. The measurement of the hole mobility of SQ is performed by using a hole only device of ITO/PEDOT-PSS/SQ/Au and ITO/ PEDOT-PSS/SQ: $\mathrm{PC}_{71} \mathrm{BM} / \mathrm{Au}$. Mobilities were calculated by fitting the dark IV characteristic with a space charge limited current (SCLC) model. eqn (1) (Fig. S2, ESI $\dagger$ ).

$$
J=\frac{9}{8} \varepsilon_{0} \varepsilon \mu_{\mathrm{h}} \frac{V^{2}}{L^{3}}
$$

where $\varepsilon_{0}$ is the permittivity of free space, $\varepsilon$ is the dielectric constant of the organic material, we assumed $\varepsilon=3,{ }^{26} V$ is the applied voltage, $L$ is the thickness of the layer and $\mu_{\mathrm{h}}$ is the mobility.

Devices with different SQ: $\mathrm{PC}_{71} \mathrm{BM}$ blend ratios by weight were fabricated and tested for their photovoltaic properties. The dark $I-V$ and rectification ratio is shown in Fig. S3 and Table S1 (ESI $\dagger$ ) respectively. The $I-V$ characteristics of the inverted $\mathrm{BHJ}$ for different ratios of $\mathrm{SQ}: \mathrm{PC}_{71} \mathrm{BM}$ in the presence of light are shown in Fig. 2c. The open circuit voltage $\left(V_{\mathrm{OC}}\right)$, short circuit current density $\left(J_{\mathrm{SC}}\right)$ and power conversion efficiency (PCE) increase as the $\mathrm{SQ}: \mathrm{PC}_{71} \mathrm{BM}$ ratio varies from $1: 0.5$ to $1: 6$ and further it remains constant or deteriorates. The origin of such improvement leading to an increase in $V_{\mathrm{OC}}, J_{\mathrm{SC}}$ and PCE to $0.68 \mathrm{~V}, 11.47 \mathrm{~mA} \mathrm{~cm}{ }^{-2}$, and $2.45 \%$, respectively, for an optimized SQ: $\mathrm{PC}_{71} \mathrm{BM}$ blend ratio of $1: 6$ depends on effective transport and transfer of free carriers created upon exciton dissociation in the BHJ OPV.

Photoluminescence (PL) quenching experiments of SQ in the presence of $\mathrm{PC}_{71} \mathrm{BM}$ show a good quenching of the PL peak of SQ at $\lambda \sim 688 \mathrm{~nm}$ (Fig. 3) even with a small amount of PCBM. The quenching does not vary much with higher PCBM content. This shows an efficient exciton quenching at the $\mathrm{SQ}: \mathrm{PC}_{71} \mathrm{BM}$ interface. $\mathrm{EQE}$ of the devices with different blend ratios provide information about the effective extraction of free carriers created by the exciton dissociation at different $\lambda$ in the spectral window of the $\mathrm{SQ}: \mathrm{PC}_{71} \mathrm{BM}$ blend.

The EQE of the inverted BHJ OPVs with different blend ratios of $\mathrm{SQ}$ and $\mathrm{PC}_{71} \mathrm{BM}$ is shown in Fig. 2d. The EQE shows further contribution from both $\mathrm{SQ}$ and $\mathrm{PC}_{71} \mathrm{BM}$. By comparing the EQE vs. $\lambda$ spectra with the absorption spectra (Fig. 2a) of individual SQ and $\mathrm{PC}_{71} \mathrm{BM}$, it can be inferred that the photocurrent in the $\lambda$ range of $300 \mathrm{~nm}$ to $600 \mathrm{~nm}$ is mostly due to $\mathrm{PC}_{71} \mathrm{BM}$ with peaks at $\lambda=360 \mathrm{~nm}, \lambda=484 \mathrm{~nm}$ and the photocurrent up to $\lambda \sim 800 \mathrm{~nm}$ is mostly due to SQ with a peak at $\lambda \sim 680 \mathrm{~nm}$. The $\mathrm{EQE}$ of the device increases steadily as the $\mathrm{SQ}: \mathrm{PC}_{71} \mathrm{BM}$ blend ratio is varied from $1: 0.5$ to $1: 6$, and for the higher PCBM 


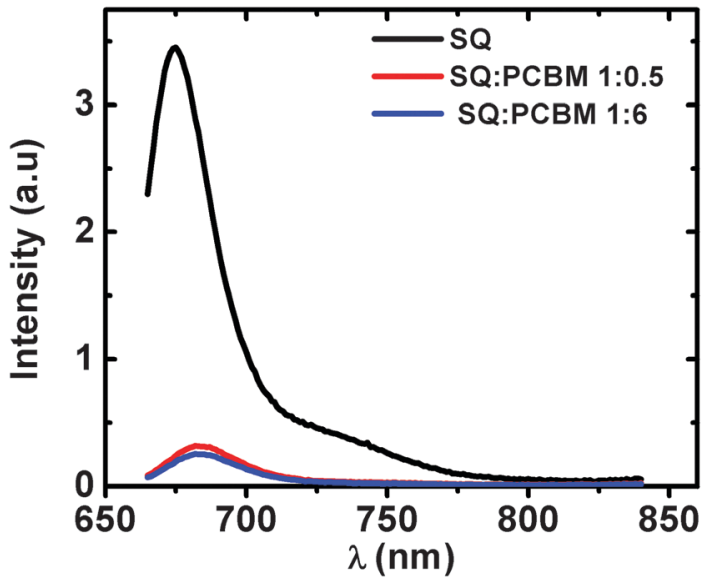

Fig. 3 PL spectra of thin films of pristine SQ, SQ:PCBM blends of blend ratios $1: 0.5$ and $1: 6$ excited at $600 \mathrm{~nm}$.

weight ratio it reduces. The optimized performance of the $\mathrm{SQ}: \mathrm{PC}_{71} \mathrm{BM}$ blend ratio of $1: 6$ can be due to balanced electron and hole transport. Deviation from this blend ratio results in a poor charge extraction and reduced EQE. This is inferred from the following observations. [(a) If the exciton dissociation was the dominant EQE mechanism, the EQE at $\lambda \sim 680 \mathrm{~nm}$ should be increased or remain the same as the absorption of SQ increases in the blend as the $\mathrm{SQ}: \mathrm{PC}_{71} \mathrm{BM}$ blend ratio is increased from 1:0.5 to 1:7. But here we observe a decrease in EQE at $\lambda \sim 680 \mathrm{~nm}$ as the $\mathrm{SQ}: \mathrm{PC}_{71} \mathrm{BM}$ blend ratio is increased from 1:6 to $1: 7$. This can be attributed to an imbalanced mobility of electrons and holes in the blend as the hole mobility of SQ is reduced significantly as the $S Q: \mathrm{PC}_{71} \mathrm{BM}$ blend ratio is varied from 1:6 to $1: 7$ (which is measured using a SCLC method as shown in Fig. 2b), (b) EQE spectra show peaks at $\lambda \sim 360 \mathrm{~nm}$, $\lambda \sim 490 \mathrm{~nm}$ and $\lambda \sim 680 \mathrm{~nm}$ similar to the absorption peaks of the blend. Most of the light is absorbed near the PFN/blend interface in the wavelength range of $300 \mathrm{~nm}<\lambda<400 \mathrm{~nm}$ and at the $\mathrm{MoO}_{3} /$ blend interface in the wavelength range of $600 \mathrm{~nm}<$ $\lambda<800 \mathrm{~nm}$. We expect a bigger ratio of EQE at $\lambda \sim 360 \mathrm{~nm}$ with respect to $\lambda \sim 680 \mathrm{~nm}$, similar to the absorption profile. But, here we observe a reduced ratio. This can be due to the recombination of holes created at the PFN/Blend interface before reaching the $\mathrm{MoO}_{3} /$ blend interface due to mobility mismatch between holes and electrons in the blend. In the case of EQE at $\lambda \sim 680 \mathrm{~nm}$ and $\lambda \sim 490 \mathrm{~nm}$, holes are created much near the $\mathrm{MoO}_{3} /$ blend interface and can be easily extracted to $\mathrm{MoO}_{3}$, without much recombination. On the other hand, the electrons created at the $\mathrm{MoO}_{3} /$ blend interface do not face much recombination as they can be easily transported through the $\mathrm{PC}_{71} \mathrm{BM}$ to $\mathrm{PFN} / \mathrm{blend}$. This explains (1) the $<1$ ratio of EQE at $\lambda \sim 360 \mathrm{~nm}$ with respect to that at $\lambda \sim 680 \mathrm{~nm}$ compared to its $>1$ ratio of absorption at the respective wavelengths, (2) comparable EQE and absorption ratios for $\lambda \sim 490 \mathrm{~nm}$ with respect to $\lambda \sim 680 \mathrm{~nm}$.] Our results are in agreement with previous reports where it is mentioned that the EQE mostly depends on the balanced electron and hole mobility in the blend rather than the exciton dissociation. ${ }^{14}$ For the highest efficiency device $(1: 6)$ the average efficiency is about
Table 1 Summary of the current-voltage characteristics for different ratios of $S Q: P C_{71} B M$ inverted solar cells under 1 Sun illumination

\begin{tabular}{llcll}
\hline $\mathrm{SQ}: \mathrm{PC}_{71} \mathrm{BM}$ ratio & $V_{\mathrm{OC}}(\mathrm{V})$ & $J_{\mathrm{SC}}\left(\mathrm{mA} \mathrm{cm}^{-2}\right)$ & $\mathrm{FF}(\%)$ & PCE $(\%)$ \\
\hline $1: 0.5$ & 0.23 & 0.34 & 28.69 & 0.25 \\
$1: 1$ & 0.38 & 5.86 & 32.12 & 0.78 \\
$1: 2$ & 0.53 & 7.11 & 28.47 & 1.18 \\
$1: 4$ & 0.65 & 7.10 & 26.54 & 1.36 \\
$1: 6$ & 0.68 & 11.47 & 31.62 & 2.45 \\
$1: 7$ & 0.53 & 7.43 & 28.13 & 0.99 \\
\hline
\end{tabular}

$55 \%$ through the UV-Vis and NIR region. The peak efficiency was $65 \%$ at $\lambda \sim 680 \mathrm{~nm}$. The $J_{\mathrm{SC}}$ calculated for the highest efficiency device from the EQE spectra by multiplying the EQE spectrum by the standard AM1.5G and integrating it over the wavelength region was in good agreement with the $J_{\mathrm{SC}}$ from current voltage $(I-V)$ experiments in the presence of AM 1.5G light of intensity 1 Sun. The calculated $J_{\mathrm{SC}}$ was $11.67 \mathrm{~mA} \mathrm{~cm}{ }^{-2}$, whereas the experimentally $(I-V)$ obtained value for the respective devices was $11.47 \mathrm{~mA} \mathrm{~cm}^{-2}$.

The $V_{\mathrm{OC}}$ of devices with different ratios of $\mathrm{SQ}: \mathrm{PC}_{71} \mathrm{BM}$ is given in Table 1 . The $V_{\mathrm{OC}}$ increases with increasing $\mathrm{PC}_{71} \mathrm{BM}$ and an optimum $V_{\mathrm{OC}}$ of $0.68 \mathrm{~V}$ is observed for devices with the $\mathrm{SQ}: \mathrm{PC}_{71} \mathrm{BM}$ blend ratio of $1: 6$. Further increase in the $\mathrm{PC}_{71} \mathrm{BM}$ content decreases the $V_{\mathrm{OC}}$. The extraction of free carriers from the devices increases as the $\mathrm{SQ}: \mathrm{PC}_{71} \mathrm{BM}$ blend ratio is increased from $1: 0.5$ to $1: 6$. This can be attributed to reduced recombination due to mismatch between the hole and electron mobility as observed in the mobility measurements of $\mathrm{SQ}: \mathrm{PC}_{71} \mathrm{BM}$ of different blend ratios. Hence the improvement in $V_{\mathrm{OC}}$ can be a result of limited recombination in the $\mathrm{BHJ} \mathrm{OPV}$ and a maximum value of $0.68 \mathrm{~V}$ is observed for optimized $\mathrm{SQ}: \mathrm{PC}_{71} \mathrm{BM}$ devices of blend ratio $1: 6$. Further increase in the $\mathrm{PC}_{71} \mathrm{BM}$ content modifies the mobility match between the holes and the electrons and results in a recombination limited extraction and reduced $V_{\mathrm{OC}}$. The devices also show a similar trend for $J_{\mathrm{SC}}$ with an optimized performance of $11.47 \mathrm{~mA} \mathrm{~cm}{ }^{-2}$ for $\mathrm{SQ}: \mathrm{PC}_{71} \mathrm{BM}$ devices with a blend ratio of $1: 6$.

Here, in the best performing device, the photocurrent $I_{\mathrm{ph}}$ shows $\mathrm{KI}^{\alpha}$ dependence on incident light intensity $I$ (where $\alpha$ is the exponential factor and $K$ is a proportionality constant), with $\alpha$ value $\sim 1$ (Fig. 4 a). This shows the properties of monomolecular or a geminate recombination mechanism. ${ }^{27,28}$ in the $\mathrm{SQ}: \mathrm{PC}_{71} \mathrm{BM}$ devices. As the intensity increases $V_{\mathrm{OC}}$ increases and saturates for higher intensities (Fig. 4b). The general expression for $V_{\mathrm{OC}}{ }^{29}$ is given in eqn (2).

$$
q V_{\mathrm{OC}}=\Delta E_{\mathrm{DA}}-\frac{\sigma^{2}}{k_{\mathrm{B}} T}-k_{\mathrm{B}} T \ln \left(\frac{N_{\mathrm{A}} N_{\mathrm{D}}}{n p}\right)
$$

The first term is the effective band gap, $\Delta E_{\mathrm{DA}}$, the second term represents disorder induced $V_{\text {OC }}$ loss, and the third term represents carrier recombination induced $V_{\text {OC }}$ loss. At low intensities $n$ and $p$ vary linearly with intensity and as a result $V_{\text {OC }}$ varies logarithmically with intensity. At higher intensity the shunt resistance $\left(R_{\mathrm{sh}}\right)$ of the device is reduced ${ }^{30}$ and hence the term $V / R_{\mathrm{sh}}$ in the practical diode equation for solar cells cannot be neglected (as shown in eqn (3)), where $T$ is the temperature, 
(a)

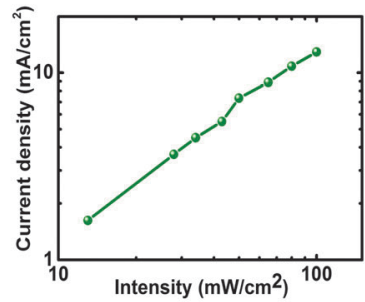

(c)

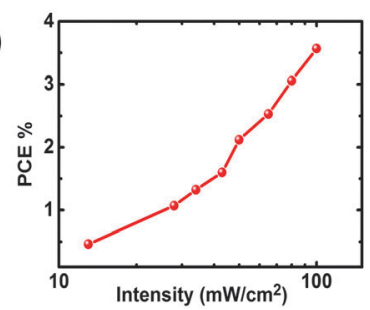

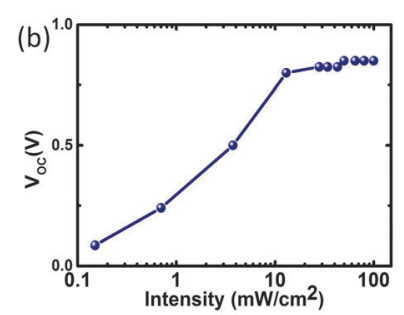

(d)

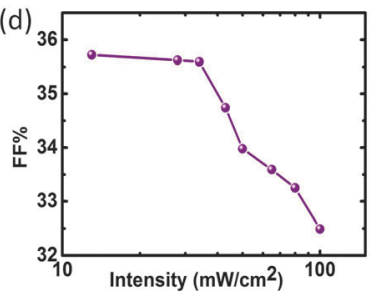

Fig. 4 Dependence of (a) $J_{S C}$ (b) $V_{O C}$ (c) PCE\% and (d) FF\% on illumination intensity of inverted $\mathrm{SQ}: \mathrm{PC} \mathrm{C}_{71} \mathrm{BM}$ photovoltaic cells blended at $1: 6$ ratios.

$k_{\mathrm{B}}$ is the Boltzmann constant, $m$ is the diode ideality factor, $J_{0}$ is the reverse saturation current density, $J_{\mathrm{ph}}$ is the photocurrent, $V$ is the output voltage, and $R_{\mathrm{S}}$ is series resistance

$$
J=\frac{R_{\mathrm{sh}}}{R_{\mathrm{sh}}+R_{\mathrm{s}}}\left\{J_{0}\left[\exp \left(\frac{q\left(V-J R_{\mathrm{s}}\right)}{m k_{\mathrm{B}} T}\right)-1\right]+\frac{V}{R_{\mathrm{sh}}}\right\}-J_{\mathrm{ph}}
$$

This again causes the reduction in $V_{\mathrm{OC}}$. So at higher intensities, the increase of $n$ and $p$ counteracts the reduction in parallel resistance $R_{\mathrm{sh}}$ and when these two effects balance, $V_{\mathrm{OC}}$ saturates. The FF of the best devices was $31.62 \%$ and this low value was attributed to large internal series resistance, which can be due to poor extraction of free carriers. A histogram of the best performing device characteristics is given in Fig. 5 .

The optimized inverted BHJ OPV shows an enhanced power conversion efficiency of $4.12 \%$ upon exposure of the device to AM1.5G light of intensity 1 Sun for 10 minutes, prior to $I-V$ measurements. The PCE vs. exposure time for the device with
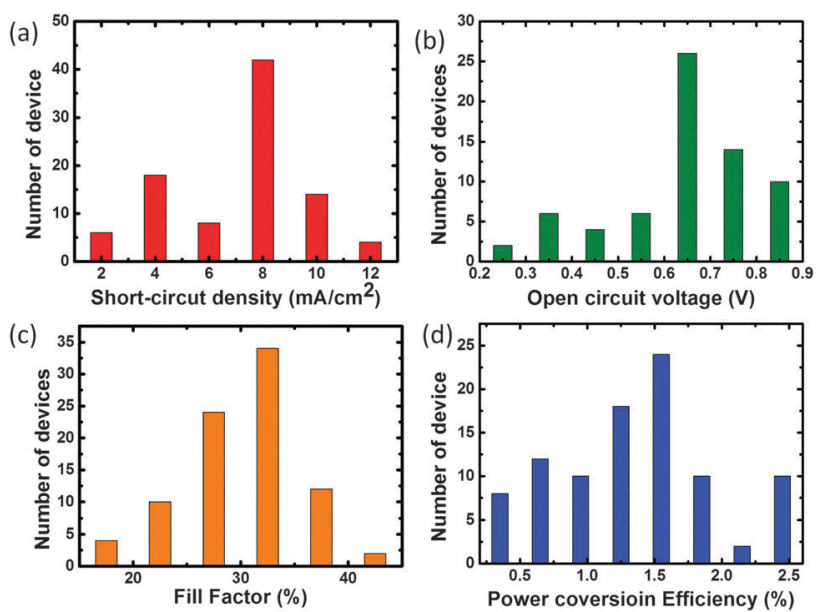

Fig. 5 Histogram of the photovoltaic performance parameters such as (a) $J_{\mathrm{SC}}$, (b) $V_{\mathrm{OC}}$, (c) FF\% and (d) PCE\% of the SQ:PC $\mathrm{P}$ BM $(1: 6)$ inverted solar cell.
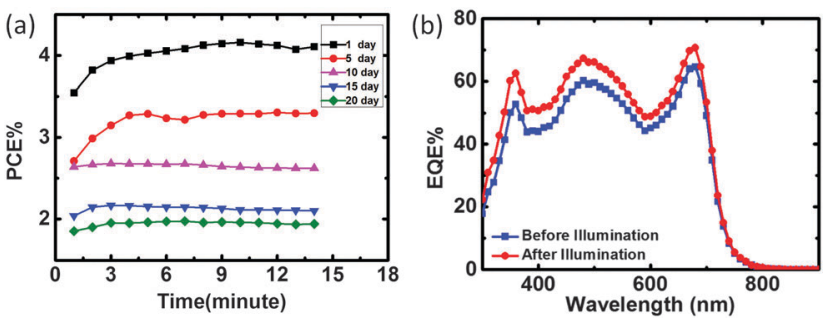

Fig. 6 (a) Illuminated AM1.5G, 1 Sun light exposure time effect on power conversion efficiency of $\mathrm{SQ}: \mathrm{PC}_{71} \mathrm{BM}$ photovoltaic device blended at a 1:6 ratio and the stability of the cell tested on different days. (b) EQE of the $S Q: P C_{71} B M(1: 6)$ device before and after continuous illumination of the device under 1 Sun illumination.

the blend ratio of $1: 6$ is shown in Fig. 6a. As the illumination time varies from one to ten minutes, PCE increases from $2.45 \%$ to $4.12 \%$ and further exposure results in a saturation of PCE at $4 \%$. Devices with other blend ratios exhibit similar behaviour. The EQE spectrum of the device before and after illumination shows an increase in EQE over the entire wavelength region without any distortion in the spectral shape (Fig. 6b). This increase in PCE and EQE upon exposure of light before the measurement can be explained by the enhanced charge carrier transport through the bulk and transfer to the electrode. The reason for the enhanced performance of the device on continuous exposure of light arises from the ITO/PFN interface. The devices were fabricated under ambient conditions; the adsorbed oxygen on the ITO caused the formation of the mid gap charge transfer states in the PFN layer near to the ITO/PFN interface. ${ }^{31}$ These states increase the work function of ITO by reducing the electric dipole moment within the PFN layer. Upon continuous light exposure, the photon excited electrons fill the mid trap states and restore the reduced dipole moment of PFN. This helps to reduce the work function of ITO as well as the charge extraction barrier, hence showing a better performance. This can be attributed to reduced recombination and enhanced free carrier transport as an improved $V_{\mathrm{OC}}$ and $J_{\mathrm{SC}}$ was observed while performing $I-V$ measurements after light
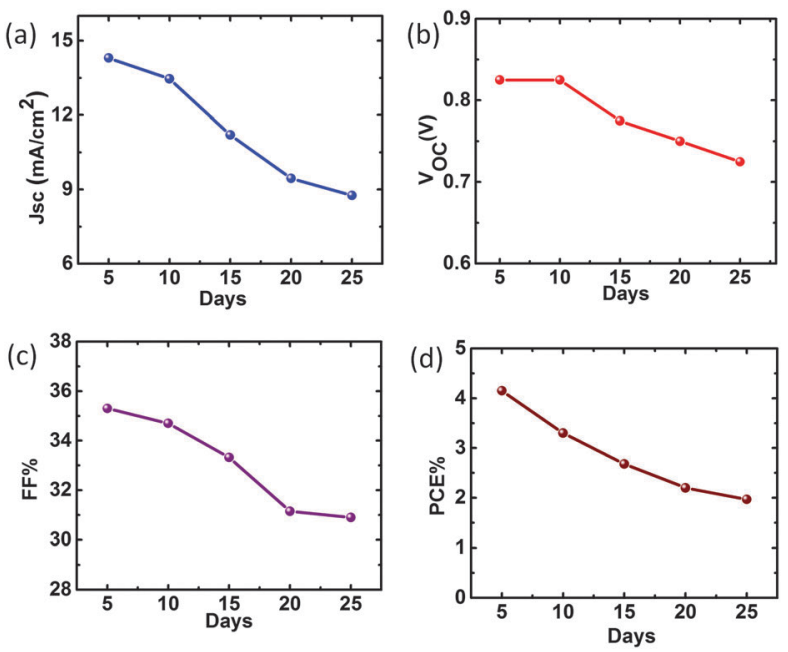

Fig. 7 Variation of solar cell parameters (a) $J_{\mathrm{SC}}$ (b) $V_{\mathrm{OC}}$, (c) FF\%, (d) PCE\% with time. 
exposure of the devices. Fig. 7 gives the variation observed in the solar cell parameters with time.

Further work is in progress to understand the origin of such an enhancement. Prolonged measurements of PCE at certain intervals of time after illumination show a small decrease in the PCE value. The stability of the devices in air was tested for a period of 1 month. The devices were unencapsulated and characterized under ambient conditions. The devices showed good stability under these conditions, with a decrease in efficiency to $2 \%$.

\section{Conclusions}

In conclusion, solution processed inverted $\mathrm{SQ}: \mathrm{PC}_{71} \mathrm{BM}$ devices were fabricated and the ratio was optimized as 1:6 with a power conversion efficiency of $2.45 \%$. The devices also showed an enhanced PCE value of $4.12 \%$ upon continuous illumination using an AM1.5G light source. The device performance parameters such as $V_{\mathrm{OC}}, J_{\mathrm{SC}}$, and EQE were studied in detail and correlated with the spectroscopy studies of SQ in the presence of $\mathrm{PC}_{71} \mathrm{BM}$. The device showed spectral response with an EQE varying from $45 \%$ to $65 \%$ over a broad solar spectral window extending to the NIR region. Intensity dependent measurements of devices showed monomolecular recombination as one of the limiting factors of the performance of the device. The air processed device showed reasonable stability for a period of one month.

\section{Acknowledgements}

We acknowledge funding from the Department of Science and Technology (DST/TM/SERI/2k11/73(G)), the Solar Energy Research Initiative project, and the Ministry of Human Resource Development both under Govt. of India.

\section{Notes and references}

1 A. Treibs and K. Jacob, Angew. Chem., Int. Ed., 1965, 4, 694.

2 A. Ajayaghosh, Acc. Chem. Res., 2005, 38, 449.

3 A. C. Tam, Appl. Phys. Lett., 1980, 37, 78.

4 C. W. Dirk, W. C. Herndon, F. Cervantes-Lee, H. Selnau, S. Martinez, P. Kalamegham, A. Tan, G. Campos and M. Velez, J. Am. Chem. Soc., 1995, 117, 2214.

5 G. J. Ashwell, G. Jefferies, D. G. Hamilton, D. E. Lynch, M. P. S. Roberts, G. S. Bahra and C. R. Brown, Nature, 1995, 375-385.

6 V. Y. Merritt and H. J. Hovel, Appl. Phys. Lett., 1976, 29, 414.

7 D. L. Morel, A. K. Ghosh, T. Feng, E. L. Stogryn, P. E. Purwin, R. F. Shaw and C. Fishman, Appl. Phys. Lett., 1978, 32, 495.
8 B. Walker, C. Kim and T.-Q. Nguyen, Chem. Mater., 2010, 23, 470 .

9 J. Roncali, Acc. Chem. Res., 2009, 42, 1719.

10 S. Sreejith, P. Carol, P. Chithra and A. Ajayaghosh, J. Mater. Chem., 2008, 18, 264.

11 G. Chen, D. Yokoyama, H. Sasabe, Z. Hong, Y. Yang and J. Kido, Appl. Phys. Lett., 2012, 101, 083904.

12 S. Wang, E. I. Mayo, M. D. Perez, L. Griffe, G. Wei, P. I. Djurovich, S. R. Forrest and M. E. Thompson, Appl. Phys. Lett., 2009, 94, 233304.

13 G. Chen, H. Sasabe, Z. Wang, X.-F. Wang, Z. Hong, Y. Yang and J. Kido, Adv. Mater., 2012, 24, 2768.

14 G. Wei, S. Wang, K. Renshaw, M. E. Thompson and S. R. Forrest, ACS Nano, 2010, 4, 1927.

15 G. Wei, S. Wang, K. Sun, M. E. Thompson and S. R. Forrest, Adv. Energy Mater., 2011, 1, 184.

16 D. Bagnis, L. Beverina, H. Huang, F. Silvestri, Y. Yao, H. Yan, G. A. Pagani, T. J. Marks and A. Facchetti, J. Am. Chem. Soc., 2010, 132, 4074.

17 Z. He, C. Zhong, S. Su, M. Xu, H. Wu and Y. Cao, Nat. Photonics, 2012, 6, 591.

18 R. Xia, D.-S. Leem, T. Kirchartz, S. Spencer, C. Murphy, Z. He, H. Wu, S. Su, Y. Cao, J. S. Kim, J. C. de Mello, D. D. C. Bradley and J. Nelson, Adv. Energy Mater., 2013, 3, 718.

19 H. J. Snaith, Nat. Photonics, 2012, 6, 337.

20 E. Zimmermann, P. Ehrenreich, T. Pfadler, J. A. Dorman, J. Weickert and L. Schmidt-Mende, Nat. Photonics, 2014, 8, 669.

21 N. J. Turro, Modern Molecular Photochemistry, 1991.

22 N. S. S. Kumar, S. Varghese, C. H. Suresh, N. P. Rath and S. Das, J. Phys. Chem. C, 2009, 113, 11927.

23 A. H. Abou El Ela and H. H. Afifi, Phys. Chem. Solids, 1979, 40, 257.

24 B. Ebenhoch, S. A. J. Thomson, K. Genevicius, G. Juška and I. D. W. Samuel, Org. Electron., 2015, 22, 62.

25 P. Cheng, Y. Li and X. Zhan, Energy Environ. Sci., 2014, 7, 2005.

26 P. W. M. Blom, M. J. M. de Jong and J. J. M. Vleggaar, Appl. Phys. Lett., 1996, 68, 3308.

27 P. Schilinsky, C. Waldauf and C. J. Brabec, Appl. Phys. Lett., 2002, 81, 3885.

28 V. D. Mihailetchi, J. Wildeman and P. W. M. Blom, Phys. Rev. Lett., 2005, 94, 126602.

29 J. C. Blakesley and D. Neher, Phys. Rev. B: Condens. Matter Mater. Phys., 2011, 84, 075210.

30 B. P. Rand, D. P. Burk and S. R. Forrest, Phys. Rev. B: Condens. Matter Mater. Phys., 2007, 75, 115327.

31 C.-Y. Nam, J. Phys. Chem. C, 2014, 118, 27219. 